\title{
Spillover: the role of bats and relationships as reservoirs of zoonotic viruses and the origin of new coronaviruses
}

\begin{abstract}
Since recent findings on coronavirus, there are numerous outstanding questions about the recent emergence of these viruses, their relationship to bats, environmental issues, gene recombinations, reservoirs, evolution and the role of human coronavirus in human infection. This review aimed to gather information about the possible origin of the new coronavirus (SARS-CoV-2) and its relationship with the alated mammals and the new strains found. Selected studies indicate that SARS-CoV-2 is a chimeric virus between a bat coronavirus and a coronavirus of unknown origin. One of the possibilities points to bats as being a reservoir originating from SARS-CoV-2 (COVID-19), transmitting to man via host source. The records indicate that a recombination between the coronaviruses of pangolins and the bat coronavirus BatCoV RaTG13 and SARS-CoV-2 human there is a common ancestry among these Betacoronaviruses, which were even identified in other mammalian species, named Ptajacu-CoV. Several questions were raised about the artificial origin of the virus by laboratory manipulation. However, although remote, further investigations are needed to rule out a probable release and the real existence of SARS-CoV-2 and beta coronaviruses, which circulate for decades among the human species.
\end{abstract}

Keywords: Chiroptera, biodiversity, zoonotic spillovers, covid-19, SARS-CoV-2, global threat

\author{
Volume 8 Issue 5 - 2020
}

Diniz Pereira Leite Júnior, ${ }^{1,2}$ Rodrigo Antônio Araújo Pires, ${ }^{3}$ Elisangela Santana de Oliveira Dantas, ${ }^{4}$ Ronaldo Sousa Pereira, ${ }^{2}$ Mário Mendes Bonci,' Regina Teixeira Barbieri Ramos,' Gisela Lara da Costa, ${ }^{5}$ Marcia de Souza Carvalho Melhem, ${ }^{6}$ Paulo Anselmo Nunes Felippe, ${ }^{3,7}$ Claudete Rodrigues Paula' 'School of Dentistry, University of São Paulo (USP), SP, Brazil ${ }^{2}$ Specialized Medical Mycology Center, Laboratory Investigation, Medicine School, Federal University of Mato Grosso (UFMT), MT, Brazil

${ }^{3}$ Department of Protection and Animal Welfare-Secretariat of Green Environment and Sustainable Development of Campinas, Prefecture of Campinas, SP, Brazil

${ }^{4}$ Institute of Biosciences, Federal University of Mato Grosso (UFMT), MT, Brazil

${ }^{5}$ Taxonomy, Biochemistry and Fungal Bioprospecting Laboratory, Oswaldo Cruz Institute (FIOCRUZ), RJ, Brazil

${ }^{6}$ Federal University of Mato Grosso do Sul (UFMS), MS, Brazil ${ }^{7}$ State University of Campinas (UNICAMP), SP, Brazil

Correspondence: Diniz Pereira Leite Júnior, School of Dentistry, University of São Paulo, SP, Brazil, Tel +55(65)98I5I9078,Email djbiologico@gmail.com

Received: October 13, 2020 | Published: October 30, 2020

\section{Introduction}

In recent decades, the world has experienced two respiratory syndromes caused by coronavirus (CoVs) previously unknown, which have caught the attention of the medical and scientific community; these viral manifestations became known as SARS-CovV (Severe Acute Respiratory Syndrome), MERS-CoV (Middle East Respiratory Syndrome) and more currently another SARS-CoV-2 (Severe Acute Respiratory Syndrome 2) as it became known worldwide called Covid-19, because it started in 2019 and peaked in 2020; known around the world and presenting lethal and pandemic potential. Due to the immediacy of these species, the importance of conserving species of fauna and flora, including bats, recent studies have addressed that about 500 species of terrestrial vertebrates, or more, are on the verge of extinction at a faster rate than ever before. Conservation researchers report that almost one in five of the mammals identified are bats ${ }^{1}$ the survival of these species is linked to our own survival, and this becomes a worrying factor. The most recent outbreak of viral pneumonia in China, which began in mid-December 2019 that spread to other continents has some possible origins of the outbreak as evidence of connection with the sale of exotic and wild animals, probably related to trafficking and global issues. ${ }^{1}$ Studies conducted by Chinese researchers ${ }^{2,3}$ observed that some patients infected with the virus were exposed to wild animals in a wholesale market, where seafood, reptiles, rural animals, wild animals and bats were sold.
Currently processes of extinction of species on the planet, are occurring mainly due to anthropic action, associated with deliberate killings and hunting of animals, environmental changes, habitat destruction, causing diseases and climatic environmental catastrophes.

In this sense, the world in which we live is changing and biodiversity has been pointing out situations in which the planetary population must be ready to respond, particularly we must maintain a view that the health of the planet has great importance and importance in preventing the spread of viruses and other microorganisms. In this context, we provide an updated description based on current literature, addressing various aspects of global epidemiology involving bats and virus CoVs,to serve as support for the understanding of issues related to coronaviruses and SARS-CoV-2, characterizing the current COVID-19 pandemic, with emphasis on aspects and characterization of the Coronaviridae family, and the intimate relationship of viruses with mammals of the order Chiroptera and the role of bats as potential reservoirs and transmitters of viral genera. The characteristics of detailed molecular evolution, phylogenetic analyses and recombination studies were cited without further investigation.

More and more studies, analyses and research are needed to deepen the estimates of the planet's species, and these studies increasingly point to a worrying reality in relation to the existing species on the planet, in this environmental and symbiotic context the human species 
will also be affected, the results will be catastrophic if no emergency measures are taken, the results presented are probably an estimate of the number of endangered species. And that's a worrisome factor for the planet's existence.

\section{Discussion}

\section{Global biodiversity threatened}

The various harmful effects on natural ecosystems, especially forest fragmentation, have caused the reduction of the size of several populations and the disappearance of species that require large areas to survive. Compared to what is known about other mammals and birds, in relation to bats, we know very little about the current population status of most chiropterans species, which meets the prioritization and planning of conservation actions, making it a challenge. ${ }^{4}$

Human pressures on the planet are growing rapidly. An example of this pressure is the recent pandemic caused by the coronavirus (Covid-19) which we face, and we still have little to know and little to understand about the likely social, economic, political and health impacts that are globally linked to trade and the lives of many wildlife species. ${ }^{1}$ Ecologist Thomas Lovejoy ${ }^{5}$ warned of the growing situation of the planet's biodiversity, making a warning while there is still time to make changes, the fact that people are aware of the imminent crisis, which is occurring on the planet, is the crisis itself, emphasizing that projections of global extinction of the species should be projected continuously.

In places where wild species are threatened, disturbances in local biodiversity are likely to occur, affecting regional biomes. The results of these environmental events expose the extreme importance and urgency of making decisions and global actions of utmost importance and immediate to save the systems that provide vital support for all humanity. ${ }^{1}$ Often human perception can induce many people who are aware of global problems, can simply realize that the loss of these global biodiversity quotas can have no consequences and this will not and even may not make much difference. But the reality is quite troubling, and if thoughts point in that direction, these people are unamusingly mistaken.

Biodiversity studies and time space analyses are important for bat estimates in poorly evaluated regions; as defined by the study proposed by Brunbjerg ${ }^{6}$ after analyzing the environmental gradient in Denmark, selecting 130 sites for field inventories, including in his research 142 new species and 143 new occurrences for that region of the globe. Using Brazilian bats as models for this type of biodiversity studies and evaluations, Aguiar ${ }^{7}$ the enormous importance of this type of study, emphasizing that the northern regions of the Cerrado biome and the west of the Caatinga biome should be regions first researched. Each ecosystem has a defined ecosystem profile, the Brazilian Cerrado is one of the richest tropical savannas, presenting a high endemism of plants and birds and great diversity of vertebrates, reflecting one of the biological priorities; considered a "hotspot" for biodiversity conservation in determined ecosystems. ${ }^{8}$ Among bats, the nectarivore Lonchophylla bokermanni was reported as endemic of this hotspot in the Brazilian Cerrado (Brazilian savannah). ${ }^{9}$

Due to this mega diversity found in Brazil, there is a total lack of studies in about $60 \%$ of the Brazilian territory and none of the biomes are minimally sampled. ${ }^{10}$ Thus, the current diversity of bats in Brazil is still an underestimation, representing a temporary portrait of the Brazilian chiropterofauna.

\section{Coronavirus: origin and history}

Historically, when we reconstruct the historical facts, discoveries and evolutionary records of SARS-CoV-2, the virus responsible for the COVID-19 pandemic, we must include how it all began and where science has walked with the constant scientific reports presented in scientific publications. Not long ago, only two human coronaviruses HCoV-229E and HCoV-OC43 were known to cause human diseases. The first records, of the pandemic that began in December 2019 and January 2020, in the city of Wuhan (Hubei province, China) reports of cases of pneumonia linked to consumption and/or contact with live animals sold at free fairs, alerted local epidemiological authorities ${ }^{11,12}$ leaving a sinister presage in the air.

Since the outbreak of severe acute respiratory syndrome (SARS) in 2002-2004, almost two decades ago, a large number of Corona viruses related to SARS (SARS-CoV/MERS-CoV) and more recently SARS-CoV-2 have been discovered in natural reservoir hosts, bats. ${ }^{13-}$

${ }^{16}$ Previous studies related to these mammals have shown that some SARS-CoV bats have the potential to infect human mammals. ${ }^{18}$ Recent scientific reports have shown that an international team of Chinese, European and American researchers and scientists have found that the strains that gave rise to the SARS-CoV-2 virus circulate worldwide. Molecular evolution and genetic recombination studies have come to the conclusion that coronaviruses (SARS-CoV-2) have highly recombinant genetic material. Unlike other viruses that have emerged in the last two decades, coronaviruses are highly recombinagenic. ${ }^{16,19}$

These evidences have been reported in scientific records, showing that some of these viruses have been spreading to humans for decades; ${ }^{20}$ studies conducted by Wang ${ }^{18}$ found Antibodies related to SARS-Cov in population samples in China. The findings of this study showed that residents who lived near bat caves, habitats of these mammals, indicated that these populations had been infected by some of these viruses. A team of European, North American and Chinese researchers gathered information on phylogenetic dating and viral sampling, meaning that different regions of the virus genome can be derived from various sources, the virus's strains diverged from other bat viruses about 40 to 70 years ago. The probable divergent dates show that bat sarbecoviruses were estimated in 1948, 1969 and 1982, all analyses showed a match of $95 \%$. The researchers claim that strains have been circulating unnoticed for decades in bats. ${ }^{20,21}$

In this context, in Brazil, researchers performed the first coronavirus sequencing in the Brazilian Amazon region, revealing that the strain contained 9 mutations in relation to what had been initially sequenced in the capital of São Paulo, with 11 mutations. These findings point to the circulation of different strains of the virus in the country; showing greater diversity than those originated in Wuhan City, China, where the first records occurred. According to the researchers, these mutational findings do not mean greater lethality in these strains, nor do they know that these mutations have an impact on the clinical point of view, requiring further study and further studies. ${ }^{22}$

\section{Coronaviridae: classification and taxonomy}

Almost after six decades, coronaviruses have become the focus of research since the first global epidemic caused by Acute Severe Respiratory Syndrome in 2002-2003 (SARS). The family Coronaviridae (RNA virus), which comprises important human and veterinary pathogens, are responsible for causing respiratory, gastrointestinal, cardiovascular and neurological diseases. ${ }^{23}$

Three diseases that caused infections in animals were the starting point for recognition and study of the family Coronaviridae. 
Discovery of several new human respiratory pathogens, some of which, it was perceived, appeared very similar to the aviaries previously described avian infectious bronchitis virus (AIBV), caused by a Gammacoronavirus; mouse hepatitis virus (MHV) and swine gastroenteritis (TGEV), caused by Alphacoronavirus, were diseases that produced great economic damage..$^{24}$ Later it was discovered that the Viruses AIBV, TGEV, MHV, were diseases that had something in common, constituted structures on its surface observed in electron microscopy that resembled the solar corona, giving rise to the name that was eventually attributed to the group, then emerging the name Coronavirus. ${ }^{25,26}$ These researchers, in 1968, compared "the 'fringe' characteristic of projections" on the outside of the virus with the solar crown (not, as some have suggested, the tips of a crown).

Phylogenetic analyses revealed that SARS-CoV-2 is closely related (88\% similarity) with Bat SARS-like CoVs (bat-SL-CoVZC45 and bat-SL-CoVZXC21), therefore, bats may be the possible primary reservoir, ${ }^{27-30}$ which was recently completed in the coding of a new RmYN02 found in bat sharing 96\% similarity of its RNA with that of SARS-CoV-2. ${ }^{21}$

The recent discovery of a wide variety of new Coronaviruses in different host species encouraged the reclassification of the order Nidovirales, subdivided into 8 suborders, which have 14 families. ${ }^{24}$ The current classification of coronaviruses, insert this group of viruses in the kingdom Riboviria, Order Nidovirales, suborder Cornidovirineae, family Coronaviridae, recognizing two subfamilies (Orthocoronavirinae and Letovirinae). The subfamily Orthocoronavirinae presents richness of coronavirus phylogenies and consists of four genera based on their genetic properties: Alphacoronavirus $(\alpha-\mathrm{CoV})$, with 15 subgenera and 19 spp.; Betacoronavirus $(\beta-\mathrm{CoV})$, with 5 subgenera and 14 spp.,
Deltacoronavirus $(\delta-\mathrm{CoV})$ with 3 subgenera and $7 \mathrm{spp}$. and finally Gammacoronavirus $(\gamma-\mathrm{CoV})$ with 3 subgenera and 5 ssp. $^{24}$

Currently, there are seven human Coronaviruses (HCovs) recognized for causing diseases and infecting humans: HCoV 229E (1965), SARSCoV-1 (2002), MERS-CoV (2003), HCoV-NL63 (2004) and SARSCoV-2 (2019). Coronaviruses CoV-229E and HCoV-NL63 belong to the genus Alphacoronavirus, HCoV-OC43, HCoV-HKU1 (lineage A), SARS-CoV, SARS-CoV-2 (lineage B) and MERS-CoV (lineage C) viruses are part of the genus Betacoronavirus, and represent beta-covs of the greatest clinical and epidemiological importance for humans. ${ }^{2,30-33}$ SARS-CoV, MERS-CoV and SARS-CoV-2 cause severe infections and epidemics, while the other four Coronaviruses (HKU1, NL63, OC43 and 229E) are common causes of colds, associated with mild symptoms. (Figure 1)..$^{28,33-36}$

For Alfa-CoVs, the updated subgenus clusters were labeled Rhinacovirus, Setracovirus, Decacovirus, Myotacovirus, Colacovirus, Pedacovirus, Minunacovirus, Nyctacovirus with CanCoV_NTU336F, CanCoV_HLJ-071, FCoVWSU791146, FelCoV_HLJDQ. For Beta-CoVs recently recognized as subgenera Embecovirus (lineage A) CrCoV BJ232, RabCoV_HKU14, RodCoV RtMruf-CoV-2; Sarbecovirus (lineage B, associated with horseshoe bats, Rhinolophus sinicus (Andersen, 1945) and Rhinolophus affinis (Horsfield, 1823) with SARS-CoV and SARS-CoV-2) and Merbecovirus (lineage C) with TyBatCoV HK U4, Pi-BatCoV HKU5, Hp-BatCoV HKU25, ${ }^{24}$ and isolated from two Amur hedgehogs (Erinaceus amurensis/Erinaceidae) named BetaCoV Erinaceus/VMC/DEU/2012 $2^{37}$ and which are closely related to MERS-CoV; Nobecovirus (lineage D) with viral representatives RoBatCoV HKU9-4, Ro-BatCoV GCCDC1-356, and also an additional fifth subgenus Hibecovirus (Bat Hp-betaCoV/Zhejiang2013) 24,27,38 all detected in bats and could lead to global damage and epidemic outbreaks.

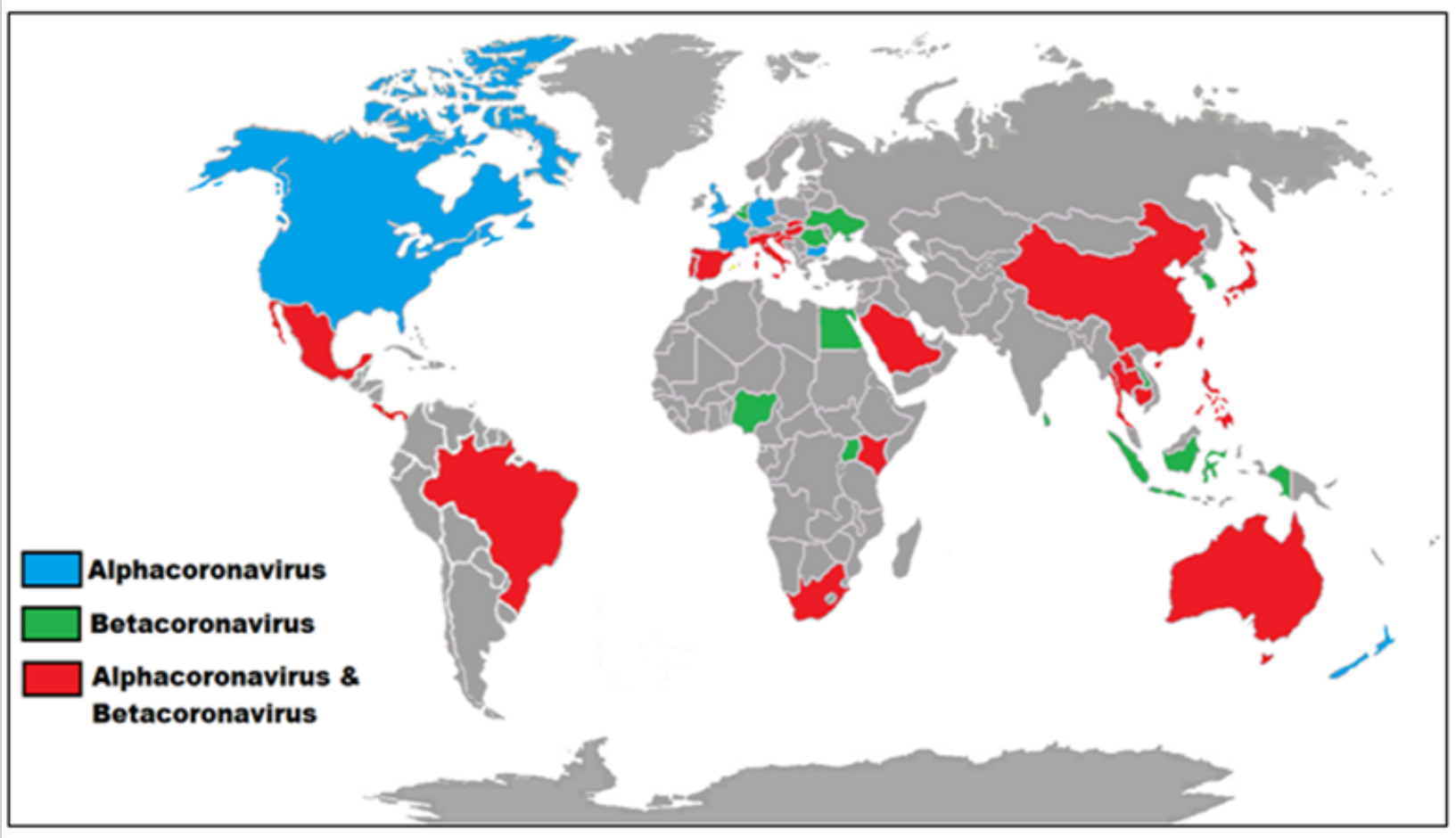

Figure I Geographic distribution of coronaviridae across the globe, highlighting the most important genera Alpha coronavirus and Beta coronavirus. In blue, regions discovered with Bats CoV for Alpha coronavirus; in green, regions discovered with Bats CoV for Betacaronavirus and in red for both genera CoV. Source:Wong et al., ${ }^{38}$ Adapted Leite-Jr, D.P. 
It is not yet known whether most of these bat CoVs have pathogenic potential in humans ${ }^{38}$ (Figure 2).

In view of the reports, bat CoVs have been proposed to be the genetic source of all Alphacoronavirus and Betacoronavirus in nature, while aviary CoVs are considered as a genetic source of all Gammacoronavirus and Deltacoronavirus ${ }^{33,34,39}$ and that have already been detected in several orders of birds, such as Anseriform, Columbiform, Charadriiform, Ciconiiform, Galliform, Passeriform, Pelecaniform and Psittaciform, which can strongly influence the epidemiology of $\mathrm{AvCoVs}^{40}$ (Figure 2).

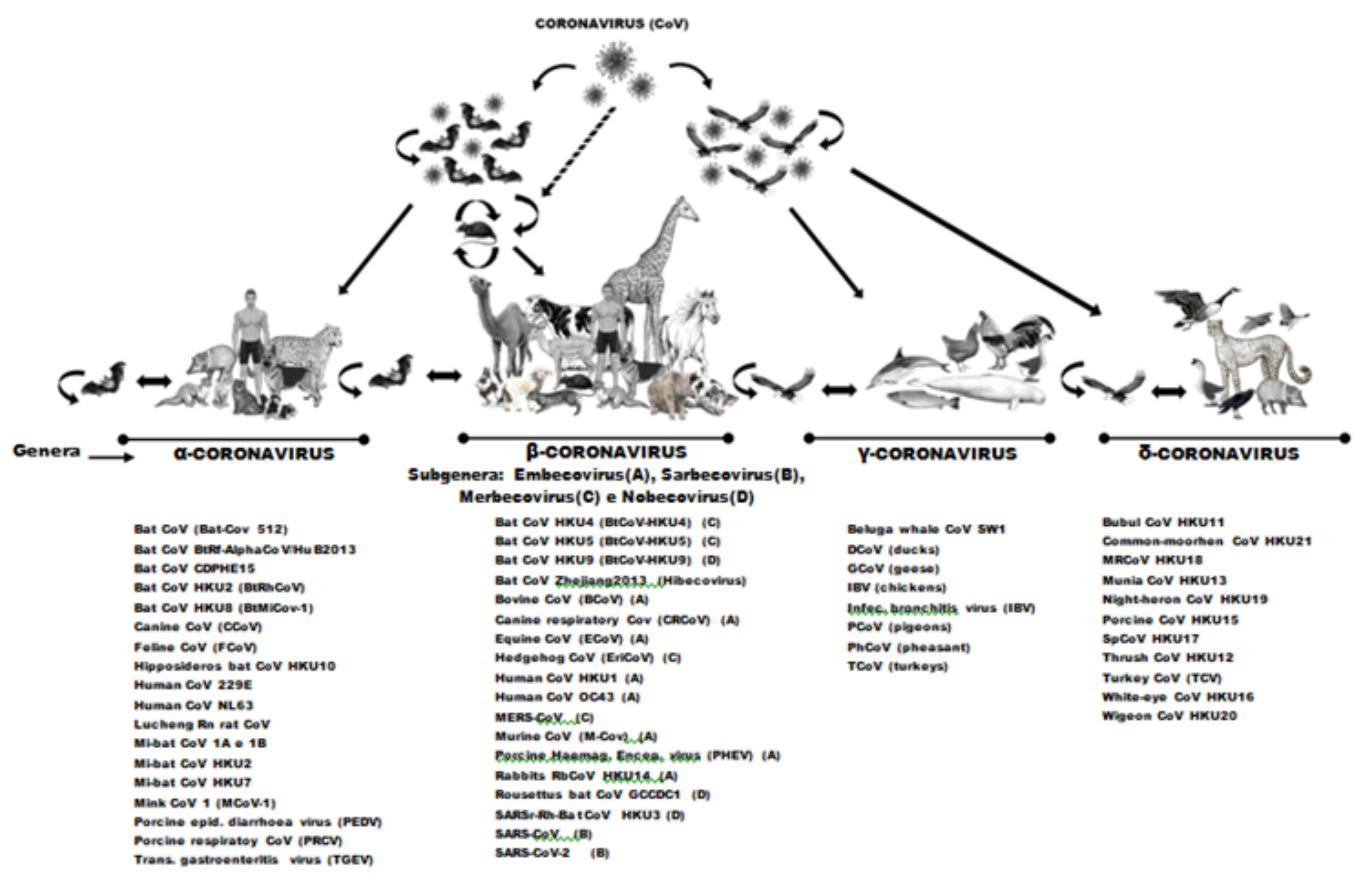

Figure 2 Schematic representation of coronavirus transmission cycles, represented the four genera of Coronavirus: Alphacoronavirus, Betacoronavirus, Gammacoronavirus and Deltacoronavirus and their respective reservoirs and hosts. Only coronavirus Alpha and Beta have the ability to infect humans. Source: ICTV, 2020. ${ }^{24}$ Images adapted: Leite-Jr, D.P.

Phylogenetic analyses in Pteropodidae bat families, Nycteridae, Molossidae, Rhinonycteridae, Hipposideridae, Rhinolophidae and Miniopteridae, carried out by researchers on islands in the Indian Ocean, revealed a great diversity of $\alpha-\mathrm{CoV}$ and $\beta-\mathrm{CoV}$, presenting a strong sign of coevolution between CoVs and their host species of bats, the evidence found by the researchers suggests host exchanges; the potential for exchanges, called overflow and potential evolutionary drivers, led to these associations. ${ }^{41}$

In 2011, Chinese researchers ${ }^{15}$ had detected and featured two new betacoronaviruses, bat isolates Bat Rp-coronavirus/Shaanxi2011 in horseshoes bat (Rhinolophus pusillus/Rhinolophidae) and Bat Cp-coronavirus/Yunnan2011 in wrinkle-lipped free-tailed bat (Chaerephon plicata/Molossidae), species found in China and the results of phylogenetic analyses confirmed the close genetic relationship between SARS-like CoVs and SARS-CoVs.

However, Chinese researchers indicate that a close relative of SARS-CoV-2 found in bats offers more evidence of natural evolution. Although it is not a direct evolutionary precursor of SARS-CoV-2, a bat corona virus in Yunnan Province, recently identified RmYN02, which contains amino acid insertions at the junction of subunits S1 and $\mathrm{S} 2$ if similarity was found in the viral peak similar to SAR-CoV-2, the results found suggest that this type of apparently unusual insertion event may occur naturally in wildlife indicating an evolution with and strong evidence that these insertion events may occur naturally in animal betacoronaviruses. ${ }^{12,21}$

This information makes it clear in our understanding that when a species disappears, the probable hosts/parasites that co-inhabit it, start looking for other species to be host. The animals that naturally host these viruses in nature, when they cease to exist or are hunted indiscriminately by the animal hunting trade, by biopiracy, by the destruction of their habitats and ecosystems, cause these microorganisms to cross the barriers of species and jump to other hosts, in these changes of hosts end up finding support in humans, and consequently the spread of diseases of wild origin. The recent events that have occurred are not the fault of biodiversity or animal species, for these zoonotic overflows, but caused by human action and the disastrous way because we insistently interact with the environment in a harmful way. This questioning sheds light on the consensus of how this can probably occur. Recently researchers from the city of Rio de Janeiro/Brazil, found a new Betacoronavirus in wild pigs (Pecari tajacu/Tayassuidae), also called catetos or caititus in the zoo of that city. The infected animals presented pulmonary, respleand spleen lesions. The analyses of the samples revealed a new type of BetaCoV, strain A, provisionally named Ptajacu-CoV. ${ }^{42}$

On the other hand, in nature there is a phenomenon called by several studies, called the "dilution effect" (decreased risk of diseases with increased diversity), that is, in the presence of several potential host species of the same pathogenic organism, offering one or more compatible host species, making a pathogen less abundant. The increase in biodiversity, there is a uniformity of species, leading to a reduction of the abundance of pathogens, thus providing its transmitting effect; and consequently becoming more difficult to contact with the human species, this phenomenon occurs in many natural systems. ${ }^{43,44}$ 
It is clearly observable that the impacts provided by the human species for the acquisition of natural resources, provide disastrous impacts when not used in a sustainable and conscious way. These anthropic effects end up contributing to the reduction of biodiversity, affecting ecosystems, bringing imbalance and these effects end up directly providing calculable effects on human, collective and planetary health. Using bats, as an experimental model of this questioning, we can observe that recombinations happen very frequently in these organisms, since these mammals even host 61 viral sources capable of infecting humans, some species, however, even harbor up to 12 different viral types. ${ }^{45}$ However, the idiosyncratic biology of bats, for example, makes these winged mammals somehow immune to coronavirus; and can greatly contribute to the analysis and development of a treatment in humans, which implies the suggestions of Lovejoy. ${ }^{46}$ What leads us to think about this whole parasitic and host process is that once installed inside the human body, SARCoV-2 uses a diverse arsenal of specialized structures and the evidence of its physiology and genetics suggests that it is among us, hiding in nature for many decades, using animals as a "smoke screen", to then manifest themselves in the form of a pandemic.

\section{Bats: the current status of mammalian hosts}

Historically, among mammals, the group of bats (Order Chiroptera; Blumenbach, 1779), with clear allusion to the peculiarity of the upper limb. It is considered the group that most took advantage in the exploitation of food resources and shelter, by transforming its upper limbs into wings. ${ }^{47}$ The Chiroptera order is a placental lineage of the middle Paleocene or early Eocene, evolved for more than 50 million years and which were initially classified in the super-order Archonta, together with the tree shrews (order Scandentia), colugos (arboreal climber) (Order Dermoptera) and primates, due to the apparent similarities between the current clate Megachiroptera and the other mammals. ${ }^{48-51}$ Evolutionary studies with other groups of mammals and even among bats from different families can provide important clues in the investigation of physiological aspects that can favor disease dissemination events. Genetic, morphological and paleontological studies have shown that bats seem to be more related to fauna originating in the supercontinent Laurasia (Northern Hemisphere, including North America, Europe, North Asia and Japan), so bats are constituted in the super-order Laurasiatheria, comprising a monophyletic lineage ${ }^{48}$ that includes together carnivores (Carnivorous Order), pangolins and scaly anteaters (Pholidota Order); ungulates of odd fingers; horses, tapirs, rinocentes etc. (Order Perissodactyla); and pigs, cattle, deer, etc. (Order Artiodactyla) with even fingers, and the Cetacean Order (dolphins and whales). ${ }^{48-50}$ The nominal origin of the term "bat" originated from the Latin mure = mur, mouse with the word "blind", thus meaning "blind rat". Bats constitute the second largest order within the Mammalia Class, losing in diversity only to rodentia make up $20 \%$ of mammalia species. ${ }^{51}$

Phylogenetic analyses classified bats into two major suborders, the Yangochiroptera or Vespertilioform comprising microbat families (microchiroptera), which are mainly insectivores, while the other called Yinpterochiroptera or Pteropodiform, consists of megabats and several species of microbat, i.e. a family Pteropodidae, called megabat (also called megachiroptera, flying foxes or frugivorous bats of the Old World) and the superfamilies of Rhinolophoidea and Rhinopomatoidea (microbat). ${ }^{52-54}$ Bats are widely distributed throughout the planet and occupy almost all terrestrial environments, being present on all continents, and being absent only on some islands of the Pacific Ocean, which are very isolated from the continent, and very cold regions, such as polar ice caps (Arctic and Antarctica) or extreme altitude regions and extreme desert regions (Figure 3).

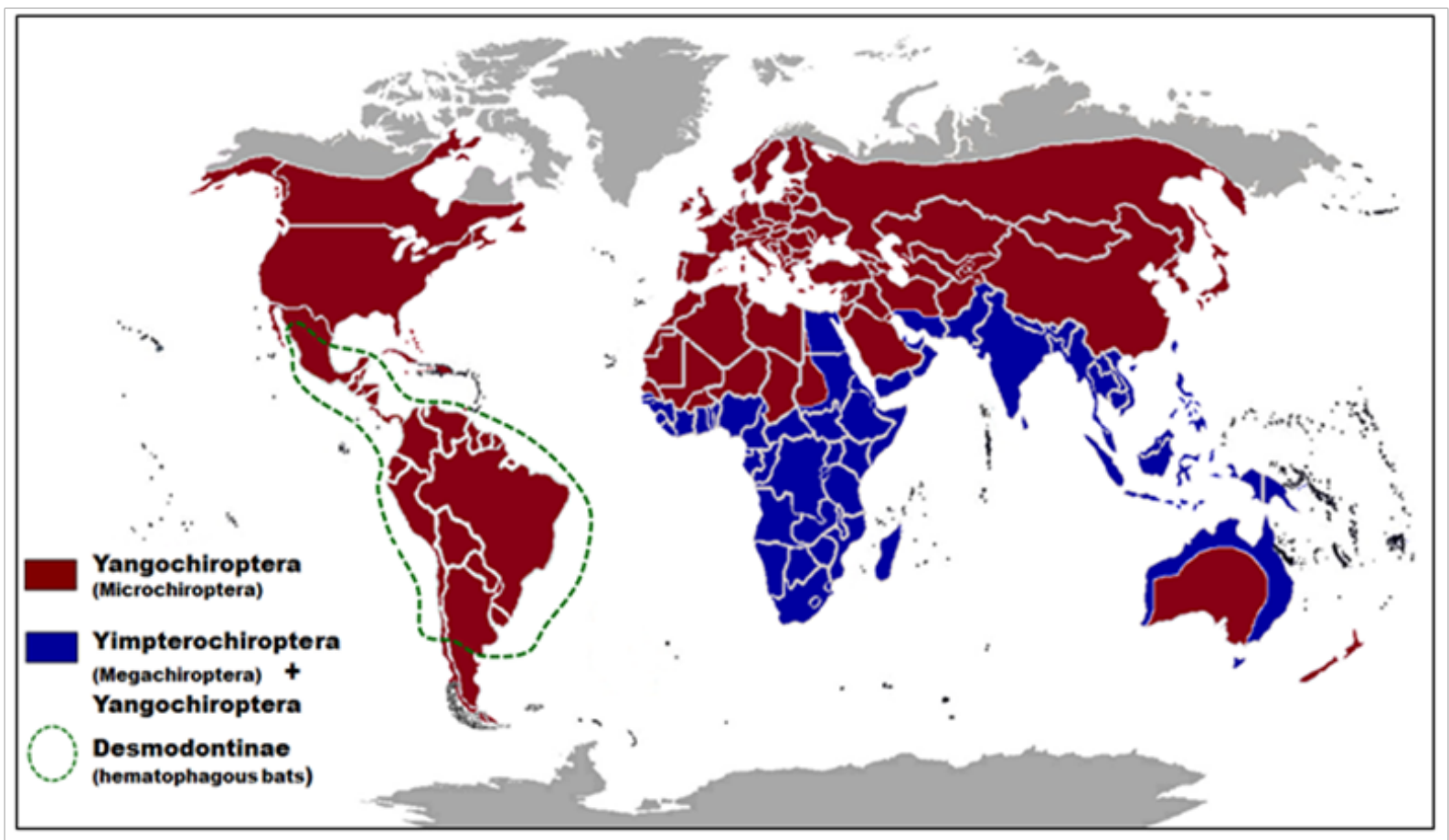

Figure 3 Phylogeographic map of regions of the globe in which there are the presence of bat species (in color), subfamily Yangochiroptera (in dark red) and Yimpterochiroptera + Yangochiroptera (in blue). The region of Latin America, northern Mexico and central Argentina surrounded in dotted green, shows where there is the presence of hematophagous bats. Source: Cooke F. Jenni, B. The encyclopedia of animals: a complete visual guid. Published by University of California Press, 2004.Adapted: Leite-Jr, D.P. 
In Brazil, a megadiverse country, it occupies the first place in the world in number of plant and mammal species, housing about $20 \%$ of the world's bat richness, in the list of countries in America with the greatest diversity: Colombia, Peru, Brazil, Ecuador, Venezuela and Mexico, being the third in the world in species richness since winged mammals, presenting records in tropical forests, there are 9 families, 14 subfamilies, 68 genera, 181 bat species officially registered in Brazil, with 10 species are endemic in the country; and currently about 1,411 species described and known worldwide. ${ }^{55}$ The families of bats that occur in the Brazilian territory are: Emballonuridae (7 genera, 17 species), Furipteridae (1 genus, 1 species), Molossidae (8 genera, 31 species), Mormoopidae (1 genus, 4 species), Natalidae (1 genus, 1 species), Noctilionidae (1 genus, 2 species), Phyllostomidae (43 genera, 93 species), Thyropteridae (1 genus, 5 species), Vespertilionidae, (5 genera, 26 species). ${ }^{55}$

Bats, which are crucial for the health of the terrestrial ecosystems in which they live, play an important ecological role, both in pollination and dispersal of various plant species, and in the control of insect pests ${ }^{56}$ has also been described as potential indicators of disturbed areas ${ }^{10,57}$ in all places where these mammals meet, including in Brazilian biomes. The monitoring of bat species and their population dynamics can act as an important indicator of ecosystem health, as they are particularly sensitive to habitat conversion and climate change. ${ }^{58}$ Reports from Aziz $^{59}$ state that $15 \%$ of bat species are listed as threatened by the IUCN, meaning they are considered vulnerable, critically endangered or endangered. About $18 \%$ of the reported species have inconsistent descriptions of information, evidencing the scarcity of ecological studies that can support evaluations of the conservation status of these winged mammals. These animals, as well as all living beings on the planet, are a network, where all are interconnected for the maintenance of habitats and are essential and important for the biodiversity of the places where they are, because they have a multitude of benefits that they provide for ecosystems.

\section{Bats: villains or victims? angels or demons?}

In chiropterans, the first description of a virus $(\mathrm{CoV})$ was reported in 2005 , when a group 1 coronavirus (alphacoronavirus) was found hosted in a bat of the genus Miniopterus; a common insectivorous bat, identified as a reservoir in Hong Kong city. Since then, coronaviruses of groups $1(\alpha-\mathrm{CoV})$ and $2(\beta-\mathrm{Cov})$ have been isolated and identified in a large number of insectivorous bat species in China, leading to the surprising conclusion that the original host of Coronavirus SARS were bats, especially the genera Myotis, Rhinolophus, Miniopteros and Scolophlus. ${ }^{60,61}$ Bats are one of the main sources of zoonotic viruses worldwide. Bats come in all shapes and sizes. Each species has its own range in what ecologists call "functional characteristics", which are biochemical, physiological or behavioral characteristics, unique to the animal. ${ }^{45,53}$ In view of the above, we observed that the protection of the habitat of these mammals, through the actions and awareness of conservation units can still be considered the main tool of action to reduce the risk of extinction of the species, but these actions of conservation and maintenance of biodiversity of the fauna of Brazil and the world, cannot depend on a single type of instrument of standardization defense and awareness.

More and more evidence has been gathered to support the origin of Sars coronavirus (SARS-CoV) in bats in the last decade. ${ }^{16}$ This loss of biodiversity is slowly leading species to decline and our conversation begins thus, showing the importance of bats as one of the pillars for the subsistence of the planet. Bats are an ecologically and taxonomically diverse group, responsible for about $1 / 5$ of mammal diversity worldwide. Many of the threats bats face (habitat loss, meat hunting, indiscriminate killing and climate change) reflect the conservation challenges of our century. ${ }^{4}$ Slaughtering bats to relieve damage to plantations and animal breeding is often based on limited or incorrect information, the ecosystem services provided by bats are not seen, leaving only the action of the damage they cause, and with little regard for the ecological role that these mammals perform (pollination, seed dispersal, pest control, etc.). ${ }^{59}$ Bats are among the animals that cause the most aversion to humans, and it is difficult to reduce or end the feeling of rejection or the notion that the presence and proximity of bats are dangerous, harmful and undesirable. ${ }^{47}$ The main belief that all bats are vampires, often human attitudes, are prone to actions with catastrophic and negative situations of destruction of natural shelters and places where these animals nest. ${ }^{62}$ Cases since the beginning of the pandemic have been recorded worldwide of destruction of shelters, persecution, vandalism, aggression, injury to bat populations..$^{63}$ As with disgusting myths that bats suck blood, owls are associated with bad omen birds; black cats refer to bad luck, snakes for their poison, the visit of black moths at home is foreshadowing death etc... humans forget that these animals are responsible for the pollination of plants and the natural control of pests and rodents, which are responsible for causing disease, attacking crops and contaminating stored food. ${ }^{47}$

The beliefs, folklore and popular disinformation associated with the mystification of horror films, inspired by medieval legends, end up imposing on the human subconscious manifestations and crendices that end up contributing to generate dread and fear. So for lay people, every bat is scary, it's vampire, sucks blood, transmits diseases and attacks humans; this is a negative and erroneous and totally wrong thinking, which end up impacting a bad reputation on these mammals. Attributing negative situations to animals is the result of a pure lack of information that will happen until the human being assumes his own ignorance. In fact, bats occupy a wide geographical distribution and have a great diversity of species. They are considered potential sources of viral strains, because they harbor high genetic variability, capable of infecting man and animals. Therefore, these animals can act as sentinels, since they can introduce pathogens in commercial breeding and even in the human population. ${ }^{64}$

Bats are diverse and ecologically important, but are also subject to a number of serious threats, their population trajectories suggest that the declines probably resulted from the combined effect of multiple threats, which remain poorly understood and indicate the need for greater conservation efforts of the species, where many of them are at risk of extinction. ${ }^{65}$

One of the major concerns caused by the action of a biological agent, is leading researchers from the University of Kentucky (USA) to the problems generated in the extinction caused in the periods of hibernation of bat species, causing the relative vulnerability of the species to infection caused by the White Nose Syndrome (WNS) caused by the distribution of the fungus Pseudogymnoascus destructans (Crytidiomycota). ${ }^{66}$ This disease, caused by the coldloving fungus, the animals infected by this eukaryotic agent can no longer control their body temperature: during periods of hibernation, they exhaust their reserves and starve to death ${ }^{67}$ decimating bat populations and harming their survival.

Records of phylogenetic analyses performed by researchers in Brazil indicate that since 2015, metagenomic analyses of viral agents in Tadarida brasiliensis (Molossidae), opportunistic and generalist insectivore, a species involved in the dissemination of viruses, including Coronaviruses $(\mathrm{CoV})$ and a typical species in the Americas adapted to urban areas, highlighting the importance for sanitary and epidemiological surveillance. ${ }^{68}$ 
There are bats that feed on fruits, fish, amphibians and blood (only 3 species globally are vampires), but the vast majority of bat species feed on insects and, in doing so, provide a crucial service to the ecosystem. ${ }^{69}$ Reports of identification of coronavirus group 2 (BatCoV DR/2007) in a vampire bat Desmodus rotundus (Phillostomidae), a small bat with leaf nose native to Latin America and through phylogenetic analyses of ORF1b revealed to be the isolate, of a unique lineage in the group 2 of archetypical coronaviruses,${ }^{70}$ showing the importance of isolation for the epidemiology of public health, because of its role of rabies of herbivores, suffers control of their populations ${ }^{47}$ their famous history for being hosts of the rabies virus, cause this stigma becomes a zoonosis of great relevance in Brazil.

Despite the harmfulness attributed to hematophagous bats. This group of mammals of the family Phillostomidae, and sub-family Desmodontinae, which belongs to Desmodus rotundus and still includes the species Dyphilla ecaudata and Diaemus youngi that feed on blood and curiously occur only in Latin America, in northern Mexico to central Argentina (Figure 3), have an active ingredient in their salivas, the "draculin" that inhibits blood clotting, ${ }^{71}$ another curiosity stands out that puppies of hematophagous bats, in addition to consuming milk, consume the mother's excrement, to acquire bacteria such as Aeromonas hydrophilla, necessary for the digestion of the blood they consume when they reach adulthood..$^{72}$

The species Desmodus rotundus has been studied due to the antithrombolysinic action of draculin presenting relaxing vessel efficacy and facilitating blood flow in vascular diseases in vivo. ${ }^{73}$ Studies of this vampire bat-derived plasminogen activator, more recently referred to as desmoteplase, revealed that this protease has become attractive for the clinical development of patients with ischemic stroke. ${ }^{74}$

Phylogenetic analyses, proposed by Latinne ${ }^{75}$ show that the exchange between families and bat genera occurred more commonly in the Rhinolophidae family and in the genus Rhinolophus, host exchanges were more frequent and in host letons in alpha-CoVs and beta-CoVs, presenting a probable origin for SARS-CoV-2 in Rhinolophus spp bats. The species of this genus are widely distributed, including R. sinicus (Andersen, 1945), R. ferrumequinum (Schreber, 1774), R. macrotis (Blyth, 1844), R. pearsoni (Horsfield, 1851) and $R$. pusillus (Temminck, 1834), and are also the most frequent Carriers of SARS-CoV in China. ${ }^{13,14,16,30,39,60}$

More current research has concluded that genomic sequences are more closely related to SARS-CoV-2 compared to other coronaviruses, SARS-CoV-2 has greater genetic proximity to two bat-derived coronaviruses, bat-SL-CoVZC45 and bat-SL-CoVZXC21 (about $88 \%$ genetic correspondence), and farther from SARS-CoV-1 (about $79 \%$ identity) and MERS-CoV (about 50\% identity). ${ }^{12,13,34}$ Researchers point out that although SARS-CoV-2 is genetically similar to batcov ratg 13 coronavirus $(96 \%)$, presented in a horseshoe bat (Rhinolophus affinis: Rhinolophidae) in Yunnan Province, China in $2013,{ }^{12}$ found a divergence in BaTCoV RaTG13 for a period found in 1969, there are divergences in the region of the viral receptor ligant domain (RBD), suggesting that this bat coronavirus cannot efficiently bind to human ECA2. ${ }^{12,20,21,75}$ Chinese researchers reported a recombination between pangolin coronaviruses and bat coronavirus BatCoV RaTG13 and human SARS-CoV-2 and reported, the framing in the lineage within the genus Betacoronavirus of coronaviridae isolated from Malay pangolins (Manis javanica: Manidae) seized in counter-smuggling operations in southern China, reaching the hypothesis that is based on the existence of an intermediate host potential for SARS-CoV-2. However, coronaviruses isolated from pangolins also proved to be very distinct to represent the direct ancestors of SARS-CoV-2. ${ }^{76}$
Other questions regarding the origin of the virus were initially suggested that snakes would be the most likely animal reservoir for 2019-nCoV $\mathrm{nc}^{2,3,34}$ a hypothesis that also seems to have been refuted. But the transmission of the virus, to man probably occurred through contact, in wildlife markets that may have been marketed as carnivorous mammal's civet a Himalaya (Paguma larvata/Viverridae), the Chinese ferret-badger (Melogale moschata/Mustelidae) and raccoon dogs (Nyctereutes procyonoides/Canidae) ) $^{34,39,77}$ but which seem to be related to animal source, where this viral agent jumped from its natural reservoir, from a probable bat (Rhinolophus sinicus).

Many hypotheses were created for the beginning of the outbreak until an unlikely origin of SARS-CoV-2 was a virus artificially manipulated in a purpose-built laboratory. ${ }^{78}$ There are documented case reports that have been recorded in China, where laboratory infections have occurred, providing the escape of the SARS-CoV virus $^{79}$ and another record in Taiwan that have raised concern about the role of laboratory material in the spread of the disease. ${ }^{80}$

Corroborating this statement, in a study conducted by Memish ${ }^{81}$ in Saudi Arabia, evidence showed that genetic analyses found in stool samples of the bat species of the family Emballonuridae, known as egyptian tomb bat (Taphozous perforatus) was demonstrated the presence of a betacoronavirus with $100 \%$ nucleotide identity to MERS-CoV. The records report that pangolins are the only mammals besides bats, which have been documented as infected by a coronavirus related to SARS-CoV-2, and these reports suggest that these animals may be important hosts for coronaviruses, since these mammals of the order Pholidota and manidae family, existing 8 different species on the planet, found in the regions of Asia and Africa, are solitary animals of restricted behavior, ${ }^{82}$ reflecting their status of danger, as several species of pangolins are critically threatened with extinction on the Red List of Endangered Species of the International Union for Conservation of Nature (IUCN). ${ }^{83}$

These reflections bring to light some factors that also conform to the report of Chinese researchers ${ }^{11}$ who after performing genomic analyses suggested that the recombination with pangolin coronavirus (Manis spp.), after a complex pattern of evolutionary recombination and strong purifying selection among CoVs of host species and crossinfections with other species, possibly these viruses developed the ability to infect humans, suggesting a recombination in the evolutionary mechanisms that could lead human coronaviruses (CoVh) to become emerging and with high pandemic factor. This information, about this jump between species, can probably find an answer to these questions about the understanding factor for the evolutionary recombination of these viruses in such diverse hosts, in the phylogenetic study reports in mammals proposed by Nishirara ${ }^{84}$ highlight a proposal of close phylogenetic relationship between almost all mammals, occurring an ancestral dimorphism mainly including the order chiroptera, pholidota, ungulata and carnivora.

However, other researchers question ${ }^{85,86}$ arguing that these hypotheses still present several relationships between mammalian orders that remain controversial and cladistic relationships between mammals provide a basis for future studies in the reconstruction of classifications of orders of placental mammals suggesting a range of diverse hypotheses. Also in relation to phylogenetic questions, in a recent research conducted by Brazilian researchers, ${ }^{77}$ these researchers found answers that SARS-CoV viruses have been evolving with the ancestors of Homo sapiens, specializing and making human genes more apt since the ancestors.

The reports and conclusions described by researchers, we are led to believe that the evolutionary history of coronaviruses and especially 
SARS-CoV-2 may not be restricted to the enigmatic sphere of bats, knowing clearly that these flying mammals have a high diversity of viral sources and are relatively linked to the SARS-CoV virus, jumping from distinct species or not, but that really, we need more study by doing more careful and comprehensive analyses in various wild sources ${ }^{53}$ and even domestic, as was the case with the 1st. Record of COVID-19 infection in a cat in the city of Cuiabá central region of Brazil. The infection occurred due to the contact of the animal with its guardians. ${ }^{87}$ Brazilian researchers conducted a study on coronavirus in dogs and cats in Brazil in a review on Sars-CoV-2 in domestic animals. ${ }^{88,89}$

Attributing a direct causal relationship, such as "more species, more viruses, more danger" incriminating animal species, because it hosts infecting agents, is not correct, simply because such a relationship does not necessarily exist. There are several other variables that need to be considered in a process of zoonotic contamination and simply inbury, blame or incriminate a species for determining no dispersion of pathogens, is out of the question and a thought that should not be questionable. ${ }^{90}$

\section{Conclusion}

Bats are the group of mammals that host the largest number of viruses and among them corona viruses. Often the spread of epidemics and impact generated on human populations are often influenced by environmental, social and political factors. Scientific efforts are necessary for the knowledge of viruses transmitted by bats and other host sources, without the need for aggression to the environment, animals, thus avoiding unnecessary repercussions and slaughters. There are many explanations and arguments that lead bats to viruses, it is likely that in the coming years genome information and discoveries of new molecular technologies bring to light new knowledge and can help us design and detect the mechanisms that involve jumping between species so that we can be one step ahead before overflows occur.

\section{Authors' contributions}

The first author DPLJ conceived and designed or scope of the review. All other authors contributed to the improvement of the article, carrying out a careful review. All authors read and approved the final manuscript.

\section{Conflicts of interest}

The authors declared that there were no conflicts of interest.

\section{Acknowledgments}

For thank support provided by FAPESP - Fundação de Amparo a Pesquisa do Estado de São Paulo - Brazil and Conselho Nacional de Desenvolvimento Científico e Tecnológico $(\mathrm{CNPq})$ - Brazil, for their financial support.

\section{References}

1. Ceballos G, Ehrlich PR, Dirzo R. Biological annihilation via the ongoing sixth mass extinction signaled by vertebrate population losses and declines. PNAS. 2017;114(30):E6089-E6096.

2. Ji W, Wang W, Zhao X, et al.Homologous recombination within the spike glycoprotein of the newly identified coronavirus may boost crossspecies transmission from snake to human. J Med Virol. 2020.

3. Ji W, Wang W, Zhao X, et al. Cross-species transmission of the newly identified coronavirus 2019-nCoV. J Med Virol. 2020;433-440.
4. Frick W, Kingston T, Flanders J. A review of the major threats and challenges to global bat conservation. Ann N Y Acad Sci. 2020;1469(1):525 .

5. Lovejoy TE. Extinction tsunami can be avoided. PNAS. 2017;114(32):8440-8441.

6. Brunbjerg AK, Bruun HH, Brøndum L, et al. A systematic survey of regional multi-taxon biodiversity: Evaluating strategies and coverage. BMC Eco. 2019;19(1):43.

7. Aguiar LMS, Pereira MJR, Zortéa M, et al. Where are the bats? An environmental complementarity analysis in a megadiverse country. Diversity and Distribution. 2020:1-13.

8. Myers N, Mittermeier RA, Mittermeier CG, et al. Biodiversity hotspots for conservation priorities. Nature. 2000;403(6772):853-858.

9. Moratelli R, Dias D. A new species of nectar-feeding bat, genus Lonchophylla, from the Caatinga of Brazil (Chiroptera, Phyllostomidae). ZooKeys. 2015;514:73-91.

10. Cunto GC, Bernard E. Neotropical Bats as Indicators of Environmental Disturbance: What is the Emerging Message? Acta Chiropterologica. 2012;14(1):143-151.

11. Li Q, Guan X, Wu P, et al. Early transmission dynamics in Wuhan, China, of novel coronavirus-infected pneumonia. $N$ Engl $\mathrm{J} \mathrm{Med}$. 2020;382(13):1199-1207.

12. Zhou P, Yang XL, Wang XG, et al. A pneumonia outbreak associated with a new coronavirus of probable bat origin. Nature. 2020;579(7798):270 273

13. Li W, Shi Z, Yu M, et al. Bats are natural reservoirs of SARS-like coronaviruses. Science.2005;310(5748):676-679.

14. Ge X, Li J, Yang X, et al. Isolation and characterization of a bat SARS-like coronavirus that uses the ACE2 receptor. Nature. 2013;503(7477):535538

15. Yang L, Wu Z, Ren X, et al. Novel SARS-like betacoronaviruses in bats, China, 2011. Emerg Infect Dis. 2013;19(6):989-991.

16. Hu B, Zeng L, Yang X, et al. Discovery of a rich gene pool of bat SARSrelated coronaviruses provides new insights into the origin of SARS coronavirus. PLoS Pathog. 2017;13(11):e1006698.

17. Menachery V, Yount B, Debbink K, et al. A SARS-like cluster of circulating bat coronaviruses shows potential for human emergence. Nat Med. 2015;21(12):1508-1513.

18. Wang N, Li SY, Yang XL, et al. Serological Evidence of Bat SARSRelated Coronavirus Infection in Humans, China. Virol Sinica. 2018;33(1):104-107.

19. Lam HM, Ratmann O, Boni MF. Improved algorithmic complexity for the 3SEQ recombination detection algorithm. Mol Biol Evol. 2018;35(1):247-251.

20. Boni MF, Lemey P, Jiang X, et al. Evolutionary origins of the SARSCoV-2 sarbecovirus lineage responsible for the COVID-19 pandemic. Nat Microbiol. 2020;5(11):1408-1417.

21. Zhou $\mathrm{H}$, Chen $\mathrm{X}, \mathrm{Hu} \mathrm{T}$, et al. A novel bat coronavirus closely related to SARS-CoV-2 contains natural insertions at the S1/S2 cleavage site of the spike protein. Curr Biol. 2020;30(11):2196-2203.

22. BRASIL. Fiocruz - Fundação Oswaldo Cruz. Estudo da Fiocruz Amazônia identifica diferentes linhagens da Covid-19 no estado. 2020.

23. Schutze H. Coronaviruses in Aquatic Organisms. Aquaculture Virology. 2016;1:327-335.

24. ICTV. International Committee on Taxonomy of Viruses. ICTV Master Species List 2019.v1. EC 51, Berlim, 2020. 
25. Almeida JD, Berry DM, Cunningham $\mathrm{CH}$, et al. Virology: Coronaviruses. Nature 1968;220(5168):650.

26. Tyrrell DAJ, Almeida JD, Berry DM, et al. Coronaviruses. Nature Lond. 1968;220:650.

27. Gorbalenya AE, Baker SC, Baric RS, et al. Coronaviridae Study Group of the International Committee on Taxonomy of Viruses. Consensus Statement. Nature Microbiol. 2020;5:536-544

28. Shereen MA, Khan S, Kazmi A, et al. COVID-19 infection: Origin, transmission, and characteristics of human coronaviruses. $J$ Adv Res. 2020;24:91-98.

29. Cui J, Li F, Shi Z. Origin and evolution of pathogenic coronaviruses. Nat Rev Microbiol. 2019;17(3):181-192.

30. Hu B, Ge X, Wang LF, et al. Bat origin of human coronaviruses. Virol J. 2015;12:221.

31. MacLachlan NJ, Dubovi EJ. Fenner's Veterinary Virology. 5th ed. Cambridge, MA: Academic Press; 2017:393-413.

32. Woo PC, Lau SK, Huang Y, et al. Coronavirus diversity, phylogeny and interspecies jumping. Exp Biol Med(Maywood). 2009;234(10):11171127

33. Woo PCY, Lau SK, Lam CSF, et al. Discovery of Seven Novel Mammalian and Avian Coronaviruses in the Genus Deltacoronavirus Supports Bat Coronaviruses as the Gene Source of Alphacoronavirus and Betacoronavirus and Avian Coronaviruses as the Gene Source of Gammacoronavirus and Deltacoronavirus. J Virol. 2012;86(7):39954008 .

34. Lu R, Zhao X, Li J, et al. Genomic characterization and epidemiology 2019 novel coronavirus: implications virus origins and receptor binding. Lancet. 2020;395(10224):565-574.

35. Lim YX, Ng YL, Tam JP, et al. Human Coronaviruses: A Review of Virus-Host Interactions. Diseases. 2016;4(3):26.

36. Gaunt ER, Hardie A, Claas EC, et al. Epidemiology and Clinical Presentations of the Four Human Coronaviruses 229E, HKU1, NL63, and OC43 Detected over 3 Years Using a Novel Multiplex Real-Time PCR Method down-pointing small open triangle. J Clin Microbiol. 2010;48(8):2940-2947.

37. Lau SKP, Luk HKH, Wong ACP, et al. Identification of a Novel Betacoronavirus (Merbecovirus) in Amur Hedgehogs from China Viruses. 2019;11(11):980.

38. Wong ACP, Li X, Lau SKP, et al. Global Epidemiology of Bat Coronaviruses. Viruses. 2019;20;11(2):174.

39. Lau SK, Woo PC, Li KS, et al. Severe acute respiratory syndrome coronavirus-like virus in Chinese horseshoe bats. ProcNatl Acad Sci USA. 2005;102(39):14040-14045.

40. Domanska-Blicharz K, Jacukowicz A, Lisowska A, et al. Detection and molecular characterization of infectious bronchitis-like viruses in wild bird populations. Avian Pathol. 2014;43:406-413.

41. Joffrin L, Goodman SM, Wilkinson DA, et al. Bat coronavirus phylogeography in the Western Indian Ocean. Sci Rep. 2020;10:6873.

42. D'arc M, Cosentino MC, Moreira FRR, et al. A novel Betacoronavirus characterised in collared peccaries from the Rio de Janeiro Zoo (Brazil) killed by unknown disease. Mem Inst Oswaldo Cruz. 2020;115:e200153.

43. Keesing F, Belden LK, Daszak P, et al. Impacts of biodiversity on the emergence and transmission of infectious diseases. Nature. 2010;468(7324):647-652.

44. Ostfeld RS, Keesing F. Effects of Host Diversity on Infectious Disease Annual Review of Ecology, Evolution, and Systematics. 2012;43:157182.
45. Luis AD, Hayman DT, O'Shea TJ, et al. A comparison of bats and rodents as reservoirs of zoonotic viruses: are bats special? Proc Biol Sci. 2013;280(1756):20122753.

46. Lovejoy T. To prevent pandemics, stop disrespecting nature. National Geographic. 2020

47. Uieda W, Bred A. Bats: Neglected Agents of Sustainability. Sustainability under discussion. 2016;7(1):186-209.

48. O'Leary MA, Bloch JI, Flynn JJ, et al. The placental mammal ancestor and the post-KPg radiation of placentals. Science. 2013;339(6120):662667.

49. Nery MF, González DJ, Hoffmann FG, et al. Resolution of the laurasiatherian phylogeny: Evidence from genomic data. MolPhylogenet Evol. 2012;64(3):685-689.

50. Zhou X, Xu S, Xu J, et al. Phylogenomic analysis resolves the interordinal relationships and rapid diversification of the laurasiatherian mammals. Syst Biol. 2012;61(1):150-164.

51. Simmons NB, Seymour KL, Habersetzer J, et al. Primitive Early Eocene bat from Wyoming and the evolution of flight and echolocation. Nature. 2008;451(7180):818-821.

52. Lei M, Donga D. Phylogenomic analyses of bat subordinal relationships based on transcriptome data. Sci Rep. 2016;6:27726.

53. Olival KJ. To Cull, or Not To Cull, Bat is the Question. EcoHealth 2016;13(1):6-8.

54. Balboni A, Battilani M, Prosperi S. The SARS-like coronaviruses: the role of bats and evolutionary relationships with SARS coronavirus. Microbiologica-quarterly. J Microbiol Sci. 2012;35(1):1-16.

55. Garbino GST, Gregorin R, Lima IP, et al. Updated checklist of Brazilian bats: versão 2020. Comitê da Lista de Morcegos do Brasil. CLMB. Sociedade Brasileira para o Estudo de Quirópteros (SBEQ). 2020

56. Mello MAR, Felix GM, Pinheiro RBP, et al. Insights into the assembly rules of a continent-wide multilayer network. Nat Ecol Evol. 2019;3:1525-1532.

57. Medellín RA, Equihua M, Amin MA. Bat diversity and abundance as indicators of disturbance in netropical rainforests. Conserv. Biol. 2000;14(6):1666-1675.

58. Aodha OM, Gibb R, Barlow KE, et al. Bat detective - Deep learning tools for bat acoustic signal detection. PLOS Computational Biology. 2018 .

59. Aziz SA, Olival KJ, Bumrungsri S, et al. The Conflict Between Pteropodid Bats and Fruit Growers: Species, Legislation and Mitigation. In: Voig $\mathrm{C}$, Kingston T. editors. Bats in the Anthropocene: Conservation of Bats in a Changing World. Springer, Cham. 2016;377-426.

60. Tang XC, Zhang JX, Zhang SY, et al. Prevalence and genetic diversity of coronaviruses in bats from China. $J$ Virol. 2006;80(15):7481-7490.

61. Wang LF, Shi Z, Zhang S, et al. Review of bats and SARS. Emerg Infect Dis. 2006;12(12):1834-1840.

62. Reid JL. Restoring birds, bats, and dispersal mutualisms in a tropical agricultural landscape. University of California, Santa Cruz, 2013.

63. Zhao H. Covid-19 drive new threat to bats in China. Science. 2020;367(6485):1436

64. Felippe PA, da Silva LH, Santos MM, et al. Genetic diversity of avian infectious bronchitis virus isolated from domestic chicken flocks and coronaviruses from feral pigeons in Brazil between 2003 and 2009. Avian Dis. 2010;54(4):1191-1196.

65. Ingersoll TE, Sewall BJ, Amelon SK. Improved Analysis of LongTerm Monitoring Data Demonstrates Marked Regional Declines of Bat Populations in the Eastern United States. PLoS One. 2013;8(6):e65907. 
66. Lacki MJ, Dodd LE, Toomey RS, et al. Temporal Changes in Body Mass and Body Condition of Cave-Hibernating Bats During Staging and Swarming. J Fish Wildlife Manag. 2015;6(2):360-370.

67. Lemieux Labonté V, Simard A, Willis CK, et al. Enrichment of beneficial bacteria in the skin microbiota of bats persisting with whitenose syndrome. Microbiome. 2017;5.

68. Simas PVM. Metagenomic viral of Tadarida brasiliensis bats Institute of Biology, State University of Campinas. Doctoral thesis. Advisor:Clarisse Weis Arns. Campinas, 2015.

69. Boyles JG, Cryan PM, McCracken GF, et al. Economic importance of bats in agriculture. Science. 2011;332:41-42.

70. Brandão PE, Scheffer K, Villarreal LY, et al. A Coronavirus detected in the vampire bat Desmodus rotundus. Braz J Infect Dis. 2008;12(6):466468 .

71. Fernandez AZ, Tablate A, Beguin S, et al. Draculin, the anticoagulan factor in vampire bat saliva, is a tight-binding, noncompetitive inhibitor of activated factor X Biochimica et Biophysica Acta (BBA) - Protein Structure and Molecular Enzymology. Biochim Biophys Acta. 1999;1434(1):135-1342.

72. Hanning I, Diaz Sanchez, S. The functionality of the gastrointestinal microbiome in non-human animals. Microbiome. 2015;3(1):51

73. Kakamanu R, Hodgson WC, Ravi R, et al. Vampire Venom: Vasodilatory Mechanisms of Vampire Bat (Desmodus rotundus) Blood Feeding. Toxins (Basel). 2019;11(1):26.

74. Medcalf RL. Desmoteplase: discovery, insights and opportunities for ischaemic stroke. Br J Pharmacol. 2012;165(1):75-89.

75. Latinne A, Hu B, Olival KJ, et al. Origin and cross-species transmission of bat coronaviruses in China. bioRxiv: .2020; 2020.05.31.116061.

76. Lam TTY, Jia N, Zhang YW, et al. Identifying SARS-CoV-2-related coronaviruses in Malayan pangolins. Nature. 2020;583:282-285.

77. Fam BSO, Vargas Pinilla P, Amorim CEG, et al. ACE2 diversity in placental mammals reveals the evolutionary strategy of SARS-Cov-2. Genetics and Molecular Biology. 2020;43(2):e20200104.
78. Andersen KG, Rambaut A, Lipkin WI, et al. The proximal origin of SARS-CoV-2. Nat Med. 2020;26(4):450-452.

79. Lim PL, Kurup A, Gopalakrishna G, et al. Laboratory-Acquired Severe Acute Respiratory Syndrome. N Engl J Med. 2004;350:1740-1745.

80. Orellana C. Laboratory-acquired SARS raises worries on biosafety. The Lancet Infec Dis. 2004;4(2):64.

81. Ziad A Memish, Nischay Mishra, Kevin J Olival, et al. Middle East Respiratory Syndrome Coronavirus in Bats, Saudi Arabia. Emerg Infec Dis. 2013;19(11):1819-1823.

82. Heinrich S, Wittman TA, Ross JV, et al. The Global Trafficking of Pangolins: A Comprehensive Summary of Apreensions and Trafficking Routes from 2010-2015 TRAFFIC, Southeast Asia Regional Office, Petaling Jaya, Selangor, Malaysia. Traffic Reports. 2017.

83. Challender D, Willcox DHA, Panjang E, et al. Manis javanica. The IUCN Red List of Threatened Species. 2019.

84. Nishihara H, Hasegawa M, Okada N. Pegasoferae, an unexpected mammalian clade revealed by tracking ancient retroposon insertions. Proc Nat Acad Sci USA. 2006;103(26):9929-9934.

85. Matthee CA, Eick G, Willons Munro S, et al. Indel evolution of mammalian introns and the utility of non-coding nuclear markers in eutherian phylogenetics. Mol Phylog Evol. 2007;42(3):827-837.

86. Springer MS, Burk Herrick A, Meredith R, et al. The adequacy of morphology for reconstructing the early history of placental mammals. Systematic Biology. 2007;56(4):673-684.

87. Mato Grosso. Cuiabá Diary. Cuiabá records first confirmed case in animal with Covid-19 in the country. 2020.

88. Delai RR, Kmetiuk LB, Santos AP, et al. New coronavirus and pet animals. Veterinary Clinic. 2020;35(146):20-32.

89. Morais HA. The new coronavirus and pets - May 11, 2020 update. 1105-2020.

90. Ramos Pereira MJR, Bernard E, Aguiar LMS. Bats and COVID-19: villains or victims? Biota Neotropica. 2020;20(3):20201055. 